\title{
Posterior Decompression with Fusion \& Fixation by Pedicle Screw and Rod of Thoraco Lumbar Spine: A Study of 15 Cases
}

\author{
HARADHAN DEB NATH ${ }^{1}$, KANAK KANTI BARUA ${ }^{2}$, ZILLUR RAHMAN ${ }^{3}$, MD REZAULAMIN $^{4}$, \\ MALAY KUMAR DAS ${ }^{5}$, RANJIT KUMAR ${ }^{6}$
}

\begin{abstract}
:
Background \& Objectives: Thoraco-lumbar fracture is one of the common problems in spinal injury patients. It's early management can prevent complication after injury and can improve neurological function. The treatment plan of unstable fracture is controversial. Methods: The study was carried out at the department of neurosurgery, Bangabandhu Sheikh Mujib Medical University from June 2010 to July 2011 among the patients admitted with thoraco-lumbar spine fracture. Results: A total number of 15 patients with thoracolumbar spine fracture were included in the study. Among the 15 patients, 13(86.66\%) were male. The highest number of patients were in age group of $1-20(40 \%)$ and $21-40(40 \%)$ years. The commonest cause of Thoraco-Iumbar spine injuries were fall from height which was $8(53.33 \%)$ in number. The commonest site of injury was $L_{1}$ fracture in $4(60 \%)$ patients. It was documented that bladder dysfunction and lower limb weakness were the commonest sign. It was evident that, 10(66.70\%) and 4(26.66\%) of the patients were partially and completely improved after surgery respectively and 3(10\%) of patients had wound infection. Conclusion: Thoraco-lumbar spine fracture with incomplete injury, early surgery can improve many of the patient's life.
\end{abstract}

Key word: Thoraco-lumbar, fracture, posterior decompression, fusion, fixation, pedicle screw.

Introduction:

About $64 \%$ of spine fractures occur at the thoracolumbar (TL) spine, usually at T12-L1 level and 70\% of these occur without immediate neurologic injury. Denis 3 column model of the spine attempts to identify CT criteria of instability of thoraco-lumbar spine fractures ${ }^{1}$. This model has generally good predictive value, however, any attempt to create "rules" of instability will have some inherit inaccuracy ${ }^{1}$.

The McAfee classification describes 6 main types of fractures ${ }^{2}$. A simplified system with four categories follows. Lateral and anterior most common between T6-T8 and T12-L3. Lateral Xray wedging of the vertebral body(VB) anteriorly, no loss of height of posterior VB, no subluxation. CT spinal canal intact. Disruption of the anterior end plate ${ }^{2}$.
The thoraco-lumbar injuries are the commonest spinal injuries ${ }^{3}$. The treatment of unstable fractures and fracture dislocations of thoraco-lumbar spine remains controversial ${ }^{4}$. The goal of the treatment of unstable thoraco-lumbar injuries is optimizing neural decompression while providing stable internal fixation over the least number of spinal segments ${ }^{5}$. Either anterior posterior or both approaches can be used to achieve fusion ${ }^{6}$. However, posterior approach is less extensive. Pedicle screw devices allow immediate stable fixation as the screws traverse all the three columns. The pedicle screws are passed one level above and one level below the fractured vertebra via posterior approach ${ }^{7}$.

Injuries to the thoracic and lumbar spine account for $>50 \%$ of all spinal fractures and a large portion of acute spinal cord injuries ${ }^{8}$. Given this frequency and the significant impact of these injuries,

1. Assistant Professor, Neurosurgery Bangabandhu Sheikh Mujib Medical University, Dhaka.

2. Professor Neurosurgery, Bangabandhu Sheikh Mujib Medical University, Dhaka

3. Professor Neurosurgery, Shaheed Shurawardi Medical College Hospital, Dhaka

4. Resident, Neurosurgery, Bangabandhu Sheikh Mujib Medical University, Dhaka

5. Junior Consultant, Anesthesia, Department of Plastic and Burn Unit, Dhaka Medical College, Dhaka.

6. MS, Student Neurosurgery, Bangabandhu Sheikh Mujib Medical University, Dhaka 
significant advancements have been made in the surgical treatment of thoraco-lumbar trauma. Despite the invention and continued evolution of spinal instrumentation and surgical techniques, medical decision-making in spine trauma remains controversial. Fracture treatment can vary widely, from bracing to invasive $360^{\circ}$ fusions, based on geographical, institutional, or individual preferences with little scientific basis ${ }^{8}$.

A number of classification systems have been developed in an attempt to better define thoracolumbar trauma and aid treatment decision-making. These systems are typically based on either anatomical structures (Denis Three-Column System) or on proposed mechanisms of injury (Ferguson and Allen, and the AO system) $)^{1,9}$. Overall, however, there is a paucity of strong data supporting the use of any of these systems. Additionally, there is currently no clear consensus regarding the optimal system for characterizing thoraco-lumbar fractures. An ideal system must be simple and reproducible based on commonly identified clinical and radiographic parameters. Current systems are either excessively convoluted, with an impractical number of variables, or are too simple, lacking sufficient detail to provide clinically relevant information. These limitations have yielded classification systems that are difficult to implement, have shown in-sufficient validity and reproducibility, and have not been widely popular ${ }^{10-13}$. The TLICS has been described and validated to address the shortcomings of the prior classification systems. The purpose of this paper is to review the TLICS system and to demonstrate its clinical application using 3 cases of thoraco-lumbar spine trauma.

\section{Materials \& Methods:}

The study was carried out in the department of Neurosurgery, Bangabandhu Sheikh Mujib Medical University, Dhaka. The study was undertaken during January 2010 to July 2012.

Cases were selected following the inclusion \& exclusion criteria

1. Inclusion Criteria:

- Patients of either sex admitted with incomplete lumbar spine injury.
2. Exclusion criteria:

- Those patients who were operated second time due to complication excluded in this study.

- Complete injury.

Data was collected in a form regarding clinical presentation clinical examination, investigating procedure, postoperative evaluation \& only those patients who gave consent were in included in the study.

Results:

Table-I

Distribution of patients by sex

\begin{tabular}{lcc}
\hline Sex & Number & Percentage \\
\hline Male & 13 & 86.66 \\
Female & 2 & 13.33 \\
\hline
\end{tabular}

Table-II

Distribution of patients by age $(N=15)$

\begin{tabular}{lcc}
\hline Age in years & Number & Percentage \\
\hline $1-20$ & 06 & 40.0 \\
$21-40$ & 06 & 40.0 \\
$41-60$ & 02 & 13.33 \\
$\geq 61$ & 01 & 6.67 \\
\hline Total & 15 & 100.00 \\
\hline
\end{tabular}

Table I showed the distributation of male and female were $86 \%$ and $13.33 \%$ respectively From Table II, it was evident that age group of 1-20 years and 21-40 years, belonged to the highest group.

Table-III

Distribution of patients by causes of compressive fracture $(N=15)$

\begin{tabular}{lcc}
\hline Causes & Number & Percentage \\
\hline Fall from height & 08 & 53.33 \\
Road traffic accident & 04 & 26.67 \\
Fall of heavy object on back & 02 & 13.33 \\
Pathological fracture & 01 & 6.67 \\
\hline Total & 15 & 100.00 \\
\hline
\end{tabular}

It was found (Table III) that the commonest causes of occurrence were fall from height in $8(53.33 \%)$ cases. 
Table-IV

Distribution of patients by site of compression $(N=15)$

\begin{tabular}{lcc}
\hline Site & Number & Percentage \\
\hline $\mathrm{L}_{1}$ & 09 & 60.0 \\
$\mathrm{D}_{12}$ & 05 & 33.33 \\
$\mathrm{~L}_{2}$ & 02 & 13.33 \\
\hline Total & 15 & 100.00 \\
\hline
\end{tabular}

It was evident that (Table IV), the commonest site of compression was at $L_{1}$ vertebrae (60\%), followed by $\mathrm{D}_{12}$ fracture $(33.33 \%)$.

Table-V

Distribution of patients by the types of injury $(n=15)$.

\begin{tabular}{lcc}
\hline Type & Number & Percentage \\
\hline Wedge fracture & 9 & 60.00 \\
Burst fracture & 3 & 20.00 \\
Seat belt injury & 2 & 13.33 \\
Fracture dislocation & 1 & 6.67 \\
\hline
\end{tabular}

It was documented that (Table V), the commonest fracture type was wedge fracture $9(60 \%)$.

Table-VI

Distribution of patients by type of weakness and outcome $(N=15)$

\begin{tabular}{lcc}
\hline Clinical features & Number & Percentage \\
\hline Paraparesis & 13 & 86.66 \\
Monoparesis & 02 & 13.33 \\
Bladder dysfunction & 13 & 86.66 \\
Bladder \& Bowel dysfunction & 03 & 20.0 \\
Sexual dysfunction & 02 & 13.33 \\
Bowel dysfunction & 02 & 13.33 \\
Bladder, Bowel \& Sexual dysfunction & 02 & 13.33 \\
Autonomic Function intact & 01 & 6.67 \\
\hline
\end{tabular}

Table VI, showed that the most of the sufferers had paraparesis (86.66\%), the remaining $13.33 \%$ had monoparesis. The result revealed that the most of the patient $(86.67 \%)$ had suffered from bladder dysfunction.
Table-VII

Distribution of the patients by complication of surgery $(n=15)$

\begin{tabular}{lcc}
\hline Complication & Number & Percentage \\
\hline Wound infection & 03 & 20.0 \\
Per operative bleeding & 01 & 6.67 \\
Respiratory distress & 01 & 6.67 \\
\hline
\end{tabular}

It was found that (Table VII), $20 \%$ of patients had wound infection and were treated by proper antibiotics and wound dressing.

Table-VIII

Distribution of the patients by outcome after surgery $(n=15)$

\begin{tabular}{lcc}
\hline Improvement & Number & Percentage \\
\hline Partially improved & 10 & 66.67 \\
Completely improved & 04 & 26.66 \\
No improvement & 01 & 6.67 \\
\hline
\end{tabular}

It was documented that $13(93.34 \%)$ of the patients improved after surgery (Table VIII).

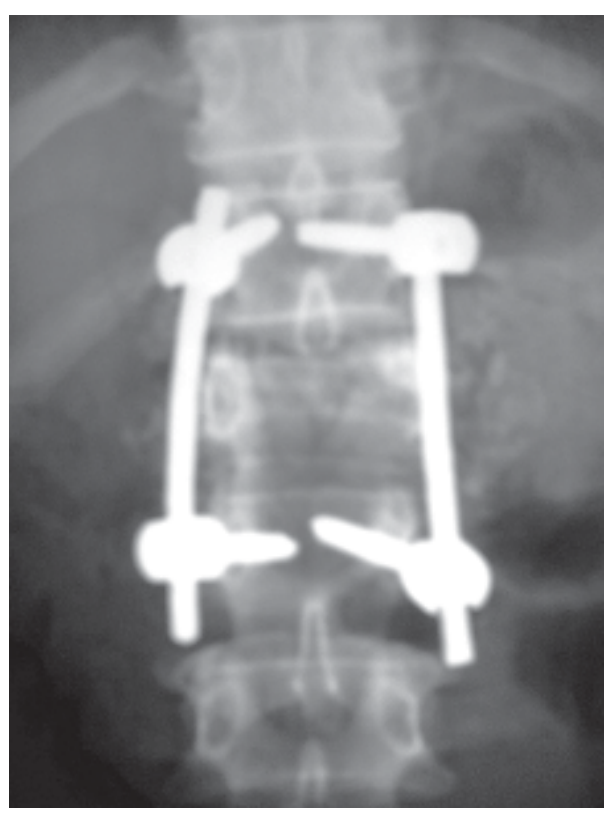

Fig.-1: Posterior fixation of $L 1$ fracture with pedicle screw and rod. 


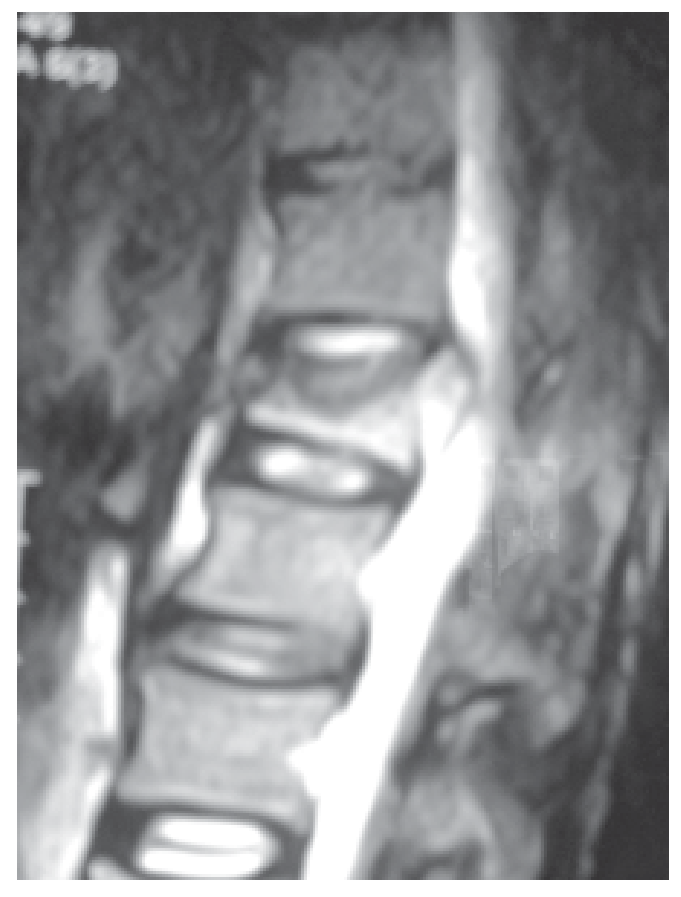

Fig.-2: L1 compression fracture

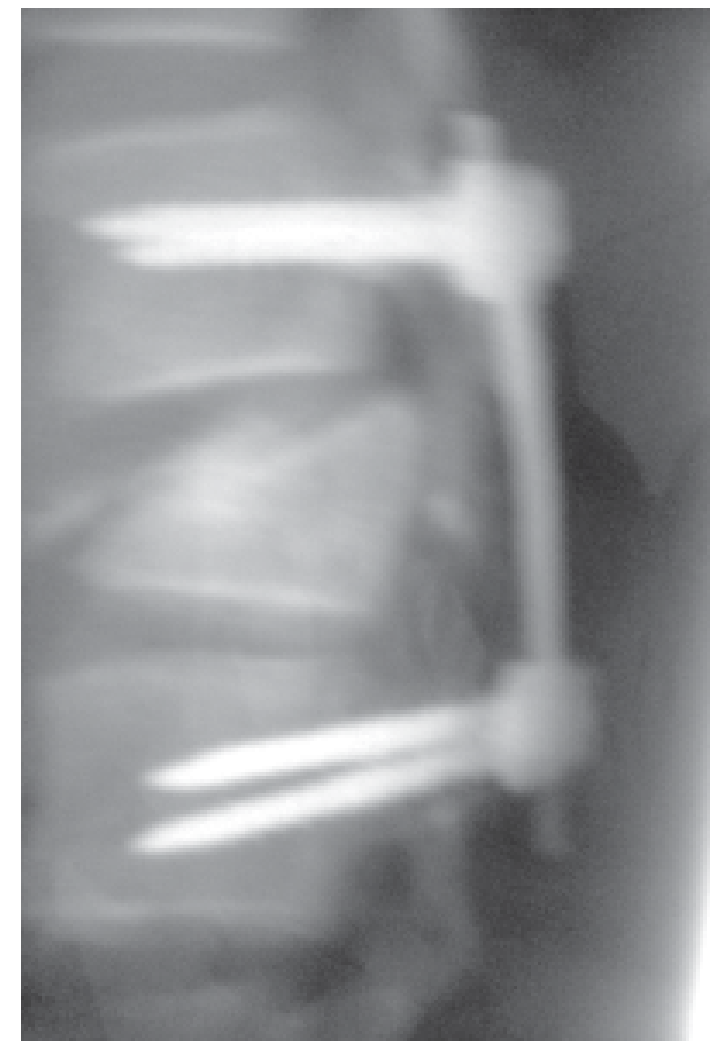

Fig.-3: Lateral view of posterior fixation of $L 1$ fracture with pedicle screw

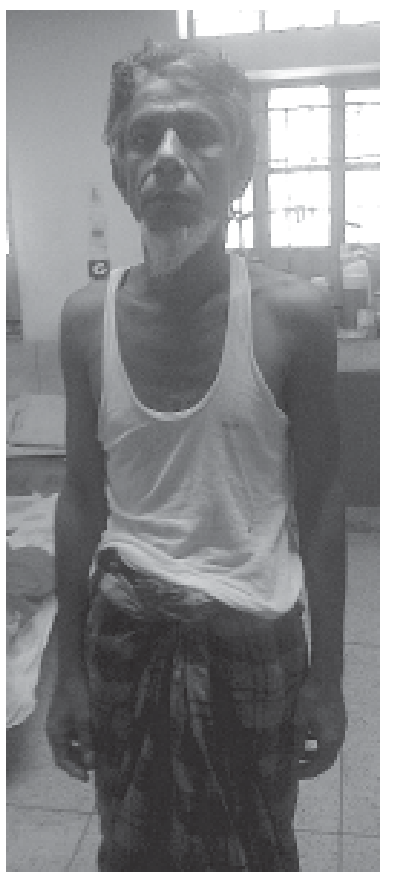

Fig.-4: Clinical improvement of patients after posterior fixation

\section{Discussion:}

Exact evaluation of the pedicles is an essential pre-requisite for posterior plating and the application of fixator systems. The pedicles are short conical tubes with an oval cross-section. The objective is to insert the screws through the center of the pedicles, approximately parallel to the upper end plates or angled downward. The screws should be aimed towards the midline to an end plate or to be angled downward. The screws should have coverage towards the midline to a certain extent, up to $20 \%$ depending on the spinal level, in order to ensure that they do not penetrate the lateral wall of the vertebral body. The long axis of the pedicle can be identified either by direct exposure or by image intensification. Although each method is reliable by itself, it is best to use a combination of the two. In addition, there are other aids for deciding screw position which are useful particularly when the anatomic landmarks are difficult to define due to distorted anatomic relationships ${ }^{14}$.

At thoracic Spine, the point of entry is just below the rim of the upper facet joint, $3 \mathrm{~mm}$ lateral to the 
center of the joint near the base of the transverse process. This screw should be angled $7-10^{\circ}$ towards the midline and $10-20 \%$ caudally ${ }^{14}$.

At lumbar spine, practically at all levels, the long axis of the pedicle pierces the lamina at the intersection of two lines: a vertical line tangential to the border of the superior articular process, and horizontal line bisecting the transverse process. Their point of intersection lies in the angle between the superior articular process and the base of the transverse process (Fig. 1). The screws should be converged by $5^{0}$ at the thoraco-lumbar junction and by $10-15^{0}$ as one progress form L2 - L $5^{14}$.

Proper placement of screws in the sacrum is difficult because of its variable anatomy. The screws may be introduced a different points and in different directions, depending upon the instrumentation and the quality of the bone. In general, the entry point is located at the intersection of two lines: a vertical line tangential to the lateral border of the S1 facet and a horizontal line tangential to the inferior border of this facet. In most cases, the screws converge towards the midline and aim towards the anterior corner of the promontory. An alternative possibility is to insert the screws more sagitally or parallel to the sacroiliac joint. The entry point shifts slightly medially as the screw direction diverges. Screws inserted parallel to the sacroiliac joint aims towards the anterior superior angle of the lateral mass of the sacrum. When positioning screws in the sacrum so as to achieve optimal purchase, it is necessary to note the density of the bone - the subchondral bone is the strongest, whereas the lateral mass of the sacrum is often very osteoporotic, some-times even hollow ${ }^{14}$.

In any case, anteroposterior (AP) and lateral preoperative $\mathrm{X}$-rays are indispensable. If there is any suggestion of anatomic variations, then $\mathrm{CT}$ scans are essential. They give information about pedicle diameter and direction; intraoperatively, the use of image intensification is indispensable, too. It confirms the location and direction of the screw. In every difficult case, intraoperative myelography with image intensification helps to identify the medial border in relationship to the nerve $\operatorname{root}^{14}$.
At the lumbar spine, the inferior and inferior lateral aspect of the pedicle can be exposed by dissecting subperiosteally from the base of the transverse process anteriorly. The soft tissues with the spinal nerve and blood vessels were carefully retracted with a curved dissector. A small curved dissector is used to probe the lateral wall of the pedicle. If necessary, the inferior part of the medial wall may also be probed. In addition, osteotomy of the base of the transverse process can help to identify the pedicle. Alternatively, the spinal canal can opened and the medial wall of the pedicle identified. The latter two techniques are usually not necessary in routine pro-cedures. At the sacral level, it is very helpful to ex-pose the S nerve root, which allows visualization of the lateral wall of the spinal canal ${ }^{15}$.

Alter identification of the entry point and the direction of the pedicle, the posterior cortex is perforated for approximately $5 \mathrm{~mm}$ using a 3.5$\mathrm{mm}$ drill, preferably with the oscillating attachment. Continued drilling of the pedicle can be dangerous. A safer technique is to prepare the entry points with the pedicle awl and to open the pedicle with a pedicle feeler. This preparation is per-formed to the junction between the pedicle and vertebral body. The circumference of the canal is checked with the tip of the $\mathrm{AO}$ depth gauge, which has an angled tip to ensure that perforation of the bone has not occurred; particularly medially. Image intensification with the gauge or a Kirschner wire in place confirms the proper position. The depth gauge may be inserted into the cancellous bone of the vertebral body and the anterior cortex is not perforated. If there is doubt regarding the depth, take a lateral radiography and ensure that the depth gauge does not penetrate more than $80 \%$ of the AP body diameter, then the anterior cortex will not be perforated $^{16}$.

In previous study the average age group were 37 years ( \pm 11.7 years), there were $9(69 \%)$ male patients and $4(31 \%)$ female patients. The average follow-up period was 30 months ( \pm 13.5 months $)^{16}$. In our study the highest age group were 1-20 years and $21-40$ years that was $6(40 \%)$. It was evident that $13(86.66 \%)$ were male and 2(13.33\%) were female. In previous study 10 patients sustained unstable burst fractures and 3 patients sustained translational injuries (fracture-dislocation) ${ }^{16}$. In our 
study $9(60 \%)$ were compressed fracture, $3(20 \%)$ (Fig. 2 and 3) were unstable burst fracture and $1(6.67 \%)$ were fracture dislocation. Surgery was performed as early as possible, provided the patients were fit for surgery. In previous study four patients experienced massive bleeding of more than $3,000 \mathrm{ml}$, and three of them sustained combined injuries, such as extremity fractures or internal organ injuries requiring surgery ${ }^{16}$. In our study 5(33.33\%) patients had dural tear.

Among the 13 study patients, neurological improvement was observed in $12(92 \%)^{7}$. In our study (Fig. 4) clinical improvement occurs in 14(93.33\%) of patients.

\section{Conclusion:}

Patient with incomplete spine injury showed good to excellent recovery and could be mobilized early with external support by pedicle screw fixation. So early surgery with posterior decompression and fusion and fixation can improved the patients neurological function.

\section{References:}

1. Denis F. The three column spine and its significance in the classification of acute thoracolumbar spinal injuries. Spine 1983;8:817-31.

2. Chedid MK, Green C. A Review of the management of lumbar fractures with focus on surgical decision making and techniques. Contemp Neurosurg 1999;21(11):1-12.

3. Yue JJ, Sossan A, Selgrath C, Deutsch LS, Wilkens K, Testaiuti M. Gabriel JP. The treatment of unstable thoracic spine fractures with transpedicular screw instrumentation: a 3-year consecutive series. Spine. 2002;27(24):2782-7

4. Shafiq K, Iqbal M, Hameed A, Mian JM. Role of transpedicular fixation in thoracolumbar spinal injuries. Neurol Surg 1998;1:21-7.

5. Sar C, Bilen FE. Flexion was more painful than extension. Thoracolumbar flexiondistraction injuries combined with vertebral body fractures. Am J Orthop 2002;31: 147-51.

6. Biomechanical evaluation of pedicle screws versus pedicle and laminar hooks in the thoracic spine. Spine J. 2006;6(4):444-9.
7. Lindsey C, Deviren V, Xu Z, Yeh RF, Puttlitz $\mathrm{CM}$. The effects of rod contouring on spinal construct fatigue strength. Spine 2006;31(15): 1680-87.

8. National SCI Statistical Center (US): Spinal Cord Injury Facts \& Figures at a Glance 2008. Birmingham, AL, The National SCI Statistical Center, 2008.

9. Ferguson $\mathrm{RL}$, Allen $\mathrm{BL}$ Jr: A mechanistic classification of thoracolumbar spine fractures. Clin Orthop Relat Res 1984;189: 77-88.

10. Magerl F, Aebi M, Gertzbein SD, Harms J, Nazarian S: A comprehensive classification of thoracic and lumbar injuries. Eur Spine J 1994;3:184-201.

11. Blauth $M$, Bastian L, Knop C, Lange U, Tusch G: Inter-observer reliability in the classification of thoraco-lumbar spinal injuries. Orthopade 1999;28:662-681, 1999

12. Magerl F, Aebi M, Gertzbein SD, Harms J, Nazarian S: A comprehensive classification of thoracic and lumbar injuries. Eur Spine J 1994;3:184-201.

13. Oner FC, Ramos LM, Simmermacher RK, Diekerhof $\mathrm{CH}$, Dhert WJ, Verbout AJ: Classification of thoracic and lumbar spine fractures: problems of reproducibility. A study of 53 patients using CT and MRI. Eur Spine J 2002;11:235-245.

14. Wood KB, Khanna G, Vaccaro AR, Arnold PM, Harris MB, Mehbod AA: Assessment of two thoracolumbar fracture classification systems as used by multiple surgeons. J Bone Joint Surg Am 2005; 87:1423-1429.

15. Abeil M, Thalgott JS, Weblo JK. Stabilization technique: spine AO Priciples in the spine surgery. Springer Mantra/CandevergyGermany 2002;83-122.

16. Jun DS, $\mathrm{Yu} \mathrm{CH}$, Ahh BG. Posterior Direct Decompression and Fusion of the Lower Thoracic and Lumbar Fractures with Neurological Deficit. Asian Spine J. 2011;5(3): 146-154. 